\title{
MODIFIKASI SOLAR MENJADI BAHAN BAKAR SETARA PERTAMINA DEX
}

\author{
Ika Kusuma Nugraheni \\ Jurusan Mesin Otomotif, Politeknik Negeri Tanah Laut \\ Email: ika.k.nugraheni@politala.ac.id
}

Intisari- Telah dilakukan penelitian mengenai modifikasi solar untuk dapat memiliki karakter menyerupai Pertamina DEX. Solar yang digunakan bersumber dari bahan bakar produk Pertamina yang dijual di pasaran. Uji karakter fisik menunjukkan kualitas Pertamina DEX lebih baik dibandingkan solar. Hasil analisis komponen bahan bakar menunjukkan bahwa kedua bahan bakar memiliki pola sebaran kromatogram yang serupa, hanya saja sebaran Pertamina DEX lebih sempit dibandingkan solar. Modifikasi dilakukan dengan menghilangkan fraksi ringan dan fraksi berat solar dengan cara distilasi. Hasil modifikasi dianalisis sebaran komponennya menggunakan kromatografi gas.

Hasil penelitian menunjukkan bahwa modifikasi solar menggunakan teknik distilasi menghasilkan 3 fraksi. Fraksi ini terpisahkan berdasarkan perbedaan titik didihnya. Hasil modifikasi menunjukkan bahwa fraksi 2 dan 3 memiliki sebaran komponen yang serupa dengan Pertamina Dex.

Kata kunci - Solar, Pertamina DEX, distilasi

\begin{abstract}
This Modification of Solar to become fuel with Pertamina DEX quality had been carried out. In this research, Solar are product of Pertamina. The physical properties test showed that Pertamina DEX has better quality than Solar. The result of component analysis showed that both of fuels have similar chromatogram, but Pertamina DEX has narrow pattern than Solar. The light and heavy fractions in Solar were separated by distillation.

The result of this modification showed that in this distillation can produce 3 fractions of Solar. This fractions separated by the different of boiling point. The modification result showed that the 2 nd and 3 rd fraction have the similar pattern with Pertamina Dex.
\end{abstract}

Keyword - Solar, Pertamina DEX, distillation

\section{PENDAHULUAN}

Perkembangan teknologi dan peningkatan aktivitas industri memicu peningkatan kebutuhan bahan bakar. Bahan bakar yang umumnya digunakan dalam aktivitas industri adalah bahan bakar diesel (solar). Solar diperoleh dari hasil distilasi minyak bumi yang telah mengalami proses perbaikan sifat.

Namun demikian, penggunaan solar sebagai bahan bakar mesin diesel menghasilkan gas buang dengan kandungan NOx, SOx, hidrokarbon dan partikulatpartikulat1. Untuk mengantisipasi tercemarnya udara akibat penggunaan bahan bakar, di Eropa diberlakukan standar emisi gas buang yang disebut dengan EURO. Sejak September 2010, Negara-negara Eropa telah memberlakukan standar EURO 5 untuk emisi gas buangnya, namun di Indonesia masih menggunakan standar emisi EURO 3, meskipun pada kenyataannya masih banyak kendaraan yang termasuk kategori EURO 1.

Pertamina sebagai perusahaan perminyakan Indonesia mengupayakan untuk dapat memberikan bahan bakar yang lebih ramah lingkungan dan juga memiliki kualitas lebih baik, serta untuk mengantisipasi akan adanya krisis energi. Oleh karena itu saat ini Pertamina mengeluarkan produk biosolar dan Pertamina DEX sebagai bahan bakar diesel.
Pertamina DEX (Diesel Environment X-tra) merupakan nama dagang dari solar non subsidi yang dijual dari perusahaan perminyakan "Pertamina Persero". Solar jenis ini memiliki keunggulan dibandingkan dengan jenis solar subsidi karena telah memenuhi standar emisi gas buang EURO 3, memiliki angka setana yang tinggi dengan kandungan sulfur yang rendah. Dengan kelebihan yang dimiliki oleh Pertamina DEX ini menjadikan Pertamina DEX lebih unggul dibandingkan dengan bahan bakar diesel jenis solar maupun biosolar. Keunggulan dari Pertamina DEX ini juga diiringi dengan harga yang lebih tinggi.

Keunggulan Pertamina DEX dibandingkan dengan solar dimungkinkan karena karakter dan komponen Pertamina DEX berbeda dengan solar, sehingga perlu dilakukan modifikasi terhadap solar agar dapat menjadikannya memiliki kualitas yang mendekati Pertamina DEX.

Seperti halnya dalam proses pembuatan awal bahan bakar Solar dengan cara distilasi, maka dalam penelitian ini juga akan melakukan modifikasi terhadap Solar dengan cara distilasi. Distilasi dilakukan untuk memisahkan fraksi-fraksi dalam bahan bakar berdasarkan dari perbedaan titik didihnya. Ffraksi yang memiliki titik didih terendah akan terpisahkan lebih dahulu dibandingkan dengan fraksi yang memiliki titik didih lebih tinggi. 


\section{METODE}

Solar dan Pertamina Dex yang diperoleh dari SPBU dianalisis sifat fisiknya, hasil analisis ini dibandingkan. Selain sifat fisik bahan bakar, dianalisis pula kandungan komponen bahan bakar menggunakan kromatografi gas. Kromatogram dari analisis kromatografi gas ini dibandingkan antara Pertamina Dex dan Solar.

Pemisahan fraksi ringan dan fraksi berat solar dilakukan dengan cara distilasi. Distilasi dilakukan dengan penurunan tekanan. Rangkaian peralatan distilasi dapat dilihat pada gambar 1 .

\section{Analisis Karakter Fisik Bahan Bakar}

Titik Nyala (Flash Point Pmc.c)

Penentuan titik nyala dan titik bakar ditentukan dengan metode pengujian dengan cawan uji tertutup menggunakan Pensky-Martens, ASTM D 93-58T (close cup).

Pengujian dilakukan dengan menempatkan bahan bakar ke dalam cawan dengan ketinggian sampai tanda batas, kemudian ditempatkan termometer. Nyala uji dihidupkan dan diatur diameter nyala $4 \mathrm{~mm}$. Sampel dipanaskan dengan kecepatan pemanasan 5-6oC dengan kecepatan putaran adukan 90-120 rpm selama 1 detik. Setiap kenaikan suhu tersebut, pengaduk dihentikan dan ujung nyala diarahkan ke permukaan sampel untuk mengecek nyala. Temperatur saat pertama kali munculnya nyala dicatat sebagai titik nyala

\section{Penentuan Densitas (berat jenis)}

Uji densitas atau berat jenis dilakukan dengan menggunakan piknometer ukuran $10 \mathrm{~mL}$. Piknometer kosong $(\mathrm{Pk})$, piknometer berisi air $(\mathrm{Pa})$, dan piknometer berisi sampel $(\mathrm{Pb})$ ditimbang pada suhu $15 \mathrm{oC}$. Densitas sampel diketahui dengan melalukan perhitungan menggunakan rumus berikut:

$$
\rho \_ \text {sampel }=\left(P \_b-P \_k\right) /\left(P \_a-P \_k\right) \rho \_a
$$

\section{Distilasi}

$100 \mathrm{~mL}$ sampel didistilasi pada kondisi tertentu. Pengamatan pembacaan termometer dan volum kondensat dilakukan secara sistematik.

\section{Analisis Komponen Bahan Bakar}

Analisis komponen senyawa bahan bakar dilakukan dengan menggunakan Gas Chromatography (GC). Melalui analisis ini diharapkan diketahui pola distribusi komponen masing-masing bahan bakar sehingga dapat menjadi dasar untuk memisahkannya dengan metode distilasi.

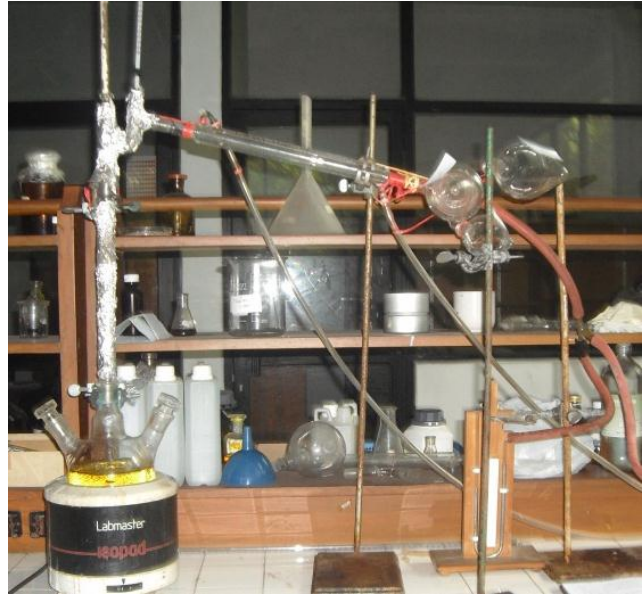

\section{Gambar 1. Rangkaian peralatan distilasi vakum}

Setelah dilakukan distilasi, dilakukan analisis menggunakan kromatografi gas untuk mengetahui susunan/sebaran komponan solar setelah modifikasi dengan cara distilasi.

\section{HASIL DAN PEMBAHASAN}

\section{Uji Karakter Fisik Solar dan Pertamina Dex}

Karakter fisik bahan bakar yang diujikan adalah titik nyala, densitas dan distilasi. Hasil analisis ketiga karakter fisik bahan bakar ini dapat dilihat pada tabel 1 .

Uji titik nyala dilakukan untuk mengetahui suhu awal bahan bakar saat pertama kali menyala. Pada uji ini terlihat bahwa Solar dan Pertamina Dex memiliki kemampuan penyalaan yang berbeda. Pertamina Dex memiliki titik nyala lebih tinggi dibandingkan dengan Solar. Uji titik nyala akan mempengaruhi kualitas penyalaan bahan bakar dalam ruang bakar mesin.

Berbeda halnya dengan uji titik nyala, pada uji densitas terlihat bahwa densitas Solar lebih tinggi dibandingkan dengan Pertamina Dex. Densitas akan berkaitan dengan banyaknya kalor yang dihasilkan per satuan volume bahan bakar, Nilai kalori akan menurun ketika densitas bahan bakar meningkat, sebaliknya kalori akan meningkat jika densitas bahan bakar rendah. Densitas bahan bakar yang rendah dapat menunjukkan bahwa bahan bakar tersebut mengandung hidrokarbon paraffin, sedangkan densitas bahan bakar yang tinggi berhubungan dengan besarnya kandungan senyawa aromatic dan naften2 .

Hasil uji distilasi menunjukkan bahawa Solar dan Pertamina Dex memiliki Initial Boling Point (IBP) / titik didih awal yang berbeda. Pertamina Dex memiliki titik didih awal jauh lebih tinggi dibandingkan dengan Solar. Dimungkinkan hal inilah yang menyebabkan Pertamina Dex memiliki titik nyala yang lebih tinggi dibandingkan dengan Solar. 
Tabel 1. Hasil Uji Karakter Fisik Solar dan Pertamina Dex.

\begin{tabular}{llccc}
\hline \multirow{2}{*}{$\begin{array}{l}\mathrm{N} \\
\text { o. }\end{array}$} & Jenis Pemeriksaan & Satuan & Solar & $\begin{array}{c}\text { Pertamina } \\
\text { Dex }\end{array}$ \\
\cline { 4 - 5 } 1. & Titik nyala Pmc.c & ${ }^{\circ} \mathrm{C}$ & 56,5 & 88,5 \\
\hline 2. & Densitas & $\mathrm{kg} / \mathrm{m}^{3}$ & 851,5 & 842,5 \\
\hline 3. & Destilasi & & & \\
\hline & I.B.P & ${ }^{\circ} \mathrm{C}$ & 159 & 196 \\
\hline 10\% vol. evap to & ${ }^{\circ} \mathrm{C}$ & 201 & 242 \\
\hline 50\% vol. evap to & ${ }^{\circ} \mathrm{C}$ & 286 & 279 \\
\hline 90\% vol. evap to & ${ }^{\circ} \mathrm{C}$ & 362 & 331 \\
\hline 95\% vol. evap to & ${ }^{\circ} \mathrm{C}$ & & 342 \\
\hline F.B.P & ${ }^{\circ} \mathrm{C}$ & 373 & 352 \\
\hline Recovery & $\%$ vol & 97 & 97,5 \\
\hline Residue & $\%$ vol & 2,5 & 2,0 \\
\hline Total Recovery & $\%$ vol & 0,5 & 99,5 \\
\hline Loss & $\%$ vol & 99,5 & 0,5 \\
\hline
\end{tabular}

\section{Analisis Komponen Bahan Bakar Sebelum Modifikasi}

Analisis komponen ini menggunakan peralatan kromatografi gas. Analisis ini bertujuan mengetahui sebaran komponen senyawa dalam kedua bahan bakar.

Hasil analisis terlihat dalam gambar 2. Hasil analisis menunjukkan bahwa Pertamina Dex memiliki pola kromatogram yang hampir serupa dengan Solar, hanya saja Solar memiliki rentang waktu retensi yang lebih panjang dibandingkan dengan Pertamina Dex. Hal ini menunjukkan bahwa untuk menyerupai pola waktu retensi Solar yang menyerupai pola kromatogram Pertamina Dex, dapat dilakukan dengan pemisahan fraksi yang memiliki waktu retensi yang rendah dan fraksi yang memiliki waktu retensi yang tinggi.

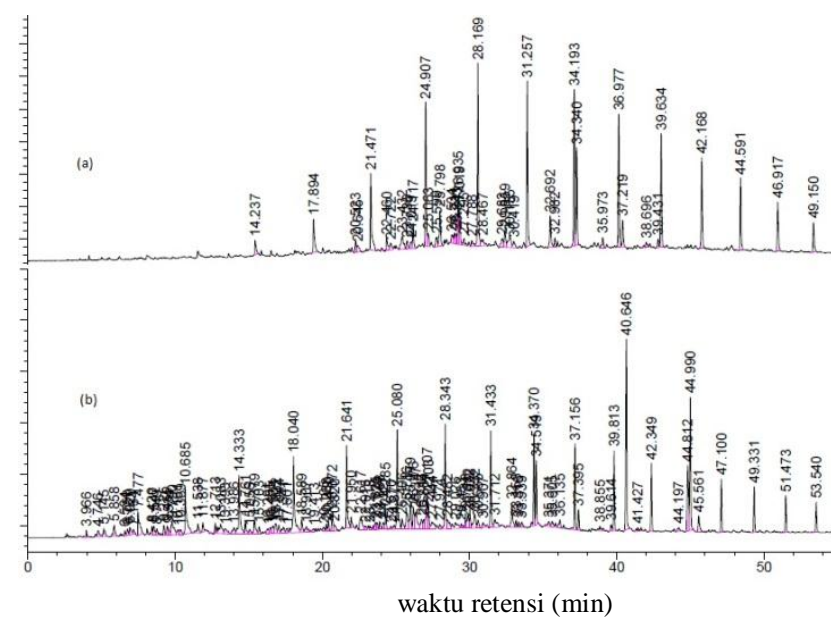

Gambar 2. (a) Pola kromatogram Pertamina Dex, (b) Pola kromatogram Solar

\section{Modifikasi Solar}

Setelah diketahui karakter Fisik dan Sebaran komponen senyawa kedua bahan bakar, maka dilanjutkan dengan modisikasi Solar. Modisikasi dilakukan dengan menghilangkan fraksi ringan dan fraksi berat Solar dengan cara distilasi. Modifikasi Solar menghasilkan 3 fraksi (gambar 3).

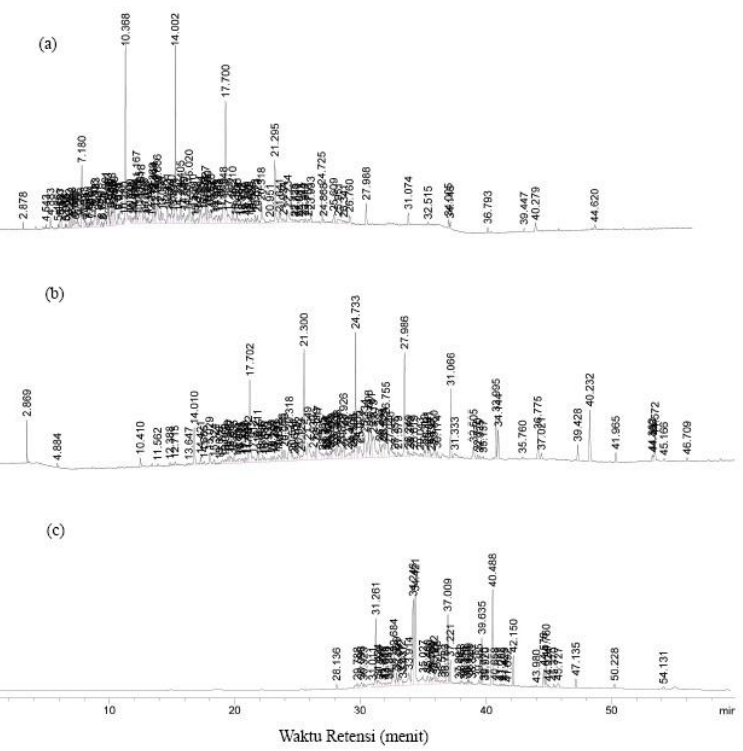

Gambar 3. Pola Kromatogram Solar hasil Distilasi (a) Fraksi 1, (b) Fraksi 2, (c) Fraksi 3.

Hasil modifikasi menunjukkan bahwa dengan pemisahan berdasarkan titik didih, Solar dapat terbagi menjadi 3 fraksi. Fraksi pertama merupakan fraksi ringan, berdasarkan pola kromatogramnya, fraksi ini belum memenuhi pola kromatogram Pertamina Dex. Fraksi 2 dan 3 terlihat lebih mendekati pola kromatogram Pertamina Dex.

\section{PENUTUP}

Solar dan Pertamina Dex merupakan produk Pertamina yang digunakan sebagai bahan bakar diesel. Kedua produk ini memiliki karakter fisik yang berbeda. Pertamina Dex dinilai memiliki karakter yang lebih baik dibandingkan dengan Solar. Analisis komponen menunjukkan bahwa Pertamina Dex dan Solar memiliki pola kromatogram yang serupa, perbedaan yang mencolok adalah pada rentang waktu retensi. Untuk membuat Solar agar memiliki pola sebaran komponen yang serupa dengan Pertamina Dex, dapat dilakukan modifikasi dengan teknik distilasi. Diharapkan Solar termodifikasi ini memiliki karakter yang menyerupai Pertamina Dex.

\section{UCAPAN TERIMA KASIH}

Terimakasih penulis haturkan kepada Bapak Prof. Dr. Triyono, SU yang telah memberikan masukan dan saran selama pengerjaan penelitian ini.

\section{DAFTAR PUSTAKA}

[1] Nasikin, M., Rita Arbianti dan Abdul Azis, 2002, Aditif Peningkat Angka Setana Bahan Bakar Solar Yang Disintesis Dari Minyak Kelapa, Makara, Teknologi, Vol. 6, No. 2. 
[2] Speight, James G., 2002, Handbook of Petroleum Product Analysis, Wiley Interscience, United States America 